- I am not a practicing physician. Do I still need to participate? Yes, physicians who are administrators or who practice in settings which do not allow them to complete a PPM or METRIC module (eg, urgent care or locum tenens) will still be required to participate in MC-FP. These Diplomates will elect to complete a different type of part IV activity. These options include a methods in medicine module (MIMM) or the patient safety module (PSM). The first MIMM will be on information management and will be available in 2007. The PSM will come on line in 2008. ABFM will be adding more MIMM options in the future which will accommodate these Diplomates.

- Are the requirements the same for everyone? In sum, the requirements are the same, however your pathway to obtaining a 3-year extension will vary somewhat, in terms of the combination of different types of modules, depending on whether or not you see patients in a clinical setting that will allow you to complete a PPM.

- I obtained my 7-year certificate in 2003. How do i extend my certificate to 2013 instead of 2010? You must hurry and complete all the requirements of the first 3-year stage by the end of 2006 to remain eligible for the 3 -year certificate extension. As an inaugural MC-FP participant, you may choose to complete either 3 SAMs or 2 SAMs and 1 PPM for your first 3-year stage to attain initial eligibility for certificate extension. This would be followed by 2 Part II modules and a Part IV module by 2009, and 2 more Part II modules and a Part IV module by 2013. You would then sit for your next examination in 2013.

- I obtained my 7-year certificate in 2004. How do i extend my certificate to 2014 instead of 2011? You must complete all the requirements of the first 3-year stage by the end of 2007 to remain eligible for the 3-year certificate extension. You may choose to complete either 3 SAMs or 2 SAMs and 1 PPM for your first 3-year stage to attain initial eligibility for certificate extension. This would be followed by 2 Part II modules and a Part IV module by 2010, and 2 more Part II modules and a Part IV module by 2014. You would then sit for your next examination in 2014.

- I will be recertifying in 2007, 2008, or 2009. Can I extend my current certification period for 3 more years? Not until you take your next recertification exam. Only Diplomates who have started MC-FP, that is, any Diplomate who has certified or recertified since 2003, may opt to extend their certification. Those Diplomates who have not yet entered MC-FP will do so after they next recertify. To clarify who is currently participating in MC-FP, approximately one half of all Diplomates have started MC-FP at this point (those Diplomates who certified or recertified in 2003,
2004, and 2005). The other half will start participating in MC-FP soon (those Diplomates who will certify or recertify in 2006, 2007, 2008 and 2009), and may choose to extend their next certification period.

- If I just want to retain or qualify for a 7-year certificate, does that mean I can dispense with taking any modules? No. Participation in MC-FP is still a requirement for eligibility to sit for the recertification examination. That is not an element of the program that has changed. You will still need to complete 6 Part II modules (currently the SAMs) and 1 Part IV module (currently the PPMs or METRIC) prior to your next exam.

More detailed information on the improvements to the MC-FP and FAQ's are available on our Web site http://www.theabfm.org by clicking on MC-FP Program Enhancements.

Tara Hornbeck
The American Board of Family Medicine

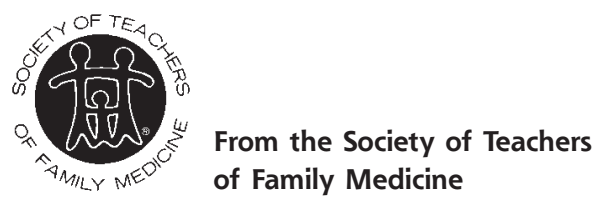

Ann Fam Med 2006:4:273-274. DOI: 10.1370/afm.586.

\section{STFM PLANS TO CHANGE THE FUTURE THROUGH PREMEDICAL SCHOOL RECRUITMENT}

STFM has taken the lead in the family organizations on Recommendation \#8 of the Future of Family Medicine report, namely "To promote a sufficient family medicine workforce." As the FFM educational programming is woven into all STFM-sponsored conferences this year, we must now consider how we take on phase 2 , "to initiate premedical school recruitment."

Now how do we do this? How do we affect the pipeline of students into family medicine before they enter medical school? Maybe we have been too passive about the recruitment into medical school. We need an intensive, personal, public relations drive by each STFM member to find 2 or 3 more of us, for the future, recruited by us from the ranks of the children and teens and young adults in the communities we serve. We guide them and mentor them and then they join us and replace us as family physicians in the community. This is particularly important if we practice with medically underserved and other vulnerable populations, since we see yearly that, with rare exception, the children in these communities have little chance of entering medical school. 
Suppose each and every family physician and educator took this on as his or her personal crusade, to fill the next generation? It seems daunting, but romantic, and yet pragmatic. We have been drawn to family medicine out of a sense of mission. Now it is time for us to pass on and rekindle that passion that drove us into this marvelous patient care field that cares for families, for communities, for whole people.

So STFM will take on several activities: (1) We will collect stories as we survey you about your current mentoring activities or those of your mentors. (2) We will survey you to find out about existing pipeline programs. (3) We will create a campaign to stimulate mentoring activities by family physicians and teachers of family physicians. (4) We will develop a toolkit with resources to support your mentoring and role modeling activities with students and schools, from grade school to college.

You can keep track of STFM's FFM activities on the STFM Web site at http://www.stfm.org/ffm/ updates.htm.

Janice Benson, MD STFM FFM Special Task Force

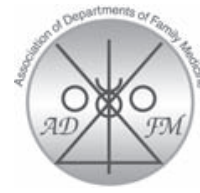

From the Association of Departments of Family Medicine

Ann Fam Med 2006;4:274-275. DOI: 10.1370/afm.568.

\section{SAVING MEDICARE: "IT'S THE WORKFORCE, STUPID!"}

A dysfunctional health care system and an aging population spell trouble for Medicare. For the 30-year period from 1970 to 2000, CMS reports a manageable $13 \%$ decline in the ratio of full-time equivalent workers to Medicare beneficiaries. However, the United States is now in the midst of a precipitous linear decline in this ratio. In 2030, there will be $40 \%$ fewer workers per Medicare beneficiary than in 2000, and sustaining Medicare as we know it will be impossible.

Starfield and colleagues have recently published a comprehensive review of the effect of primary care on the quality and costs of health care systems. ${ }^{1}$ This review demonstrates that policies designed to increase the workforce of generalist physicians have potential to dramatically reduce costs and improve quality. This is just what Medicare needs.

As we discuss strategies for Medicare reform with our legislators and regulators, 4 major areas identified in the Starfield article must be well articulated.

\section{The Ratio of Primary Care Physicians to the Total Population}

We previously summarized the work of the Dartmouth Center for the Evaluative Clinical Sciences. ${ }^{2}$ States with $40 \%$ more generalist physicians per capita had significantly better health care quality indicators and lower Medicare costs. An appropriate increase in the number of generalist physicians will lead to improved quality and savings of perhaps $\$ 60$ billion or more per year for the nation's 41 million beneficiaries.

\section{The Ratio of Generalist Physicians to the Total Physician Workforce}

Among industrialized nations, those that place a greater emphasis on generalist medicine have better health care outcomes and spend a lower percentage of GDP on health care. ${ }^{1}$ Outcomes are optimized when $40 \%$ to $50 \%$ of the total physician workforce is made up of generalist physicians. The ratio of generalist physicians to all physicians is a concept distinct from the number of generalist physicians per capita, because this ratio is a marker of the relative emphasis that a nation places upon primary care, preventive medicine, and public health. Relative to the rest of the world, the United States is poised for even higher costs and poorer outcomes. Currently, one third of US physicians are generalists. Given the rapid decrease in internal medicine residents who choose practice as generalists ${ }^{3}$ and the increasing interest in pediatric subspecialization, less than $20 \%$ of physicians who began residency in 2005 will likely practice as generalists.

\section{The Personal Medical Home}

Practice characteristics associated with improved health outcomes include first contact care, patientfocused care over time, the provision of a broad range of health services, coordinated care, family orientation, and community orientation. ${ }^{1}$ These characteristics are the foundation of the personal medical home, a term first coined by the discipline of pediatrics in 1968 and embraced by the discipline of family medicine shortly after the first reports of the Future of Family Medicine project. A system of rewards for practices that demonstrate improvements in indicators of health care quality (pay-for-performance) is currently under development by CMS. This initiative is important, but greater gains in quality and efficiency are likely to occur through the development of a pervasive system of practices that embody the characteristics of the personal medical home. In addition to payment for improvements in quality indicators, CMS should directly reward practices that demonstrate the characteristics of personal medical homes. 